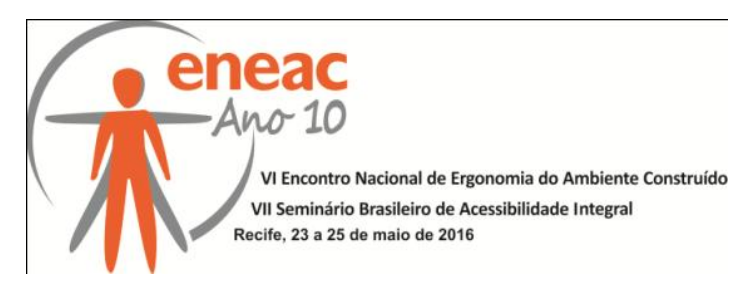

\title{
ANÁLISE ERGONÔMICA DO TRABALHO NO SETOR DE PET SHOP - BANHO E TOSA
}

\author{
LOPES BELLO, Camila; \\ CORREA FEITOSA, Keren Anne; \\ GUIMARÃES, Luiz Henrique; \\ PANCERI, Marjorie; \\ GARCIA LUPI VERGARA, Lizandra. \\ UFSC, Graduanda em Engenharia da Produção Civil \\ camilalbello@gmail.com \\ UFSC, Graduanda em Engenharia da Produção Civil \\ keren.feitosa@gmail.com \\ UFSC, Graduando em Engenharia da Produção Civil \\ lguimaraes94@gmail.com \\ UFSC, Graduanda em Engenharia da Produção Civil \\ marjorie.panceri@hotmail.com \\ UFSC, Doutora em Engenharia de Produção \\ l.vergara@ufsc.br
}

\begin{abstract}
RESUMO:
A ergonomia busca em sua essência melhorar as condições da realização das atividades humanas, tanto em relação aos seus instrumentos quanto aos ambientes em que essas atividades são realizadas, buscando sempre adaptar o trabalho ao homem. Uma das formas a avaliar riscos ergonômicos de uma empresa é com a utilização de ferramentas ergonômicas. Este estudo tem por objetivo analisar as atividades de um setor de Pet Shop em relação as cargas físicas, os aspectos ambientais e o arranjo espacial em que estão inseridos os funcionários do banho e tosa, através da ferramenta ergonômica RULA e o questionário LEST.
\end{abstract}

Palavras - chave: RULA; arranjo espacial; LEST.

\begin{abstract}
:
The ergonomics seeks in essence improve the conditions of the realization of human activities, both in relation to their instruments as the environments in which these activities are carried out, always seeking to adapt the work to the individual. One way to evaluate ergonomic risks a company is using ergonomic tools. This study aims to analyze the activities of a Pet Shop industry in relation to physical goods, the environmental aspects and the spatial arrangement that entered the bath and grooming employees through the ergonomic tools RULA and the questionnaire LEST.
\end{abstract}

Keywords: RULA; spatial arrangement; LEST. 


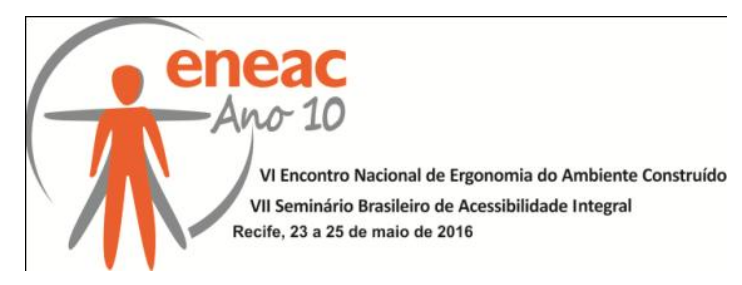

\section{INTRODUÇÃO}

Ao longo dos anos ocorreram grandes transformações socioeconômicas e tecnológicas que levaram o homem a repensar no que se diz respeito ao ambiente de trabalho e, neste contexto, viu-se a necessidade de um estudo que proporcionasse maior conforto e segurança ao ser humano a fim de realizar seu trabalho com máxima eficiência sem que sua saúde fosse afetada, tanto no aspecto mental, quanto físico. Portanto, surge a ergonomia para encontrar soluções que visam amenizar ou até mesmo eliminar problemas, adequando o ambiente de trabalho às características fisiológicas e psicológicas do trabalhador visando o conforto, a segurança e eficiência.

No presente estudo foi analisado um pet shop localizado nas proximidades da Universidade Federal de Santa Catarina (UFSC), que está em atividade desde 2001 e atualmente possui 8 funcionários. O método aplicado foi o de Análise Ergonômica do Trabalho (AET) que avalia a situação de forma qualitativa e quantitativa, através de questionários e ferramentas de avaliação ergonômica - LEST e RULA - proporcionando resultados que permitem identificar problemas e solucioná-los de forma a atender as necessidades do trabalhador e tornar suas atividades mais eficientes.

Em um contexto econômico relacionado ao ramo de pet shop, o Brasil é o segundo país com maior população de animais doméstico do mundo, o que torna uma área altamente lucrativa. De acordo com a Pesquisa Nacional de Saúde (PNS) feita pelo IBGE em 2015, o número de cães já ultrapassa o número de crianças chegando a uma média de 1,8 cachorro por domicílio. Só em Santa Catarina, a população de cães representa o dobro do número de crianças sendo 2,4 milhões de cães, além de gatos que chegam a ser mais de 732,5 mil. Segundo o SEBRAE, o mercado movimenta cerca de 14 bilhões de reais e vem crescendo $17 \%$ ao ano. Devido a grande procura por serviços de pet shop, o mercado está se sobrecarregando e a necessidade de suprir essa demanda tem se tornado um desafio para empresas do ramo.

Entre os serviços mais solicitados de pet shop encontra-se o de banho e tosa, requisitado pelos domicílios que possuem animais domésticos. Por se tratar de um serviço braçal que requer esforço físico na realização da tarefa, para se obter um resultado de qualidade em busca da satisfação do cliente, torna-se necessário um estudo mais apurado sobre as condições ao qual o trabalhador se encontra. Portanto este estudo tem como objetivo analisar as posturas adotadas pelos funcionários para a execução da tarefa, o fluxo de atividade no ambiente de trabalho, as posições das mobilhas, as ferramentas utilizadas bem como as condições ambientais, para enfim, avaliar e propor soluções que eliminam ou pelo menos amenizam os riscos de acidentes ergonômicos e possíveis problemas de saúde ao banhista.

De acordo com Vergara e Ribet (2012), "um ambiente pode ser considerado funcional se possuir uma boa distribuição espacial, tanto das áreas de funções principais quanto da ligação entre estes ambientes", assim, um novo layout foi proposto a fim de facilitar o fluxo entre as várias atividades realizadas.

Inicialmente foram observados alguns problemas ambientais, tais como: excesso de pêlo no ambiente, odor desagradável, ambiente demasiadamente quente e contato excessivo com água e produtos químicos. Outros fatores que desfavorecem a realização adequada da tarefa é o mau posicionamento das ferramentas de tosa e a falta de antiderrapante na escada de apoio da banheira, podendo gerar possíveis acidentes por escorregamento. $O$ excesso de ruído decorrente dos sopradores e as dores de coluna estão entre as principais reclamações. Para posições inadequadas que provocam dores nas costas Hecksher, Brito e Mariano (2009) recomenda que se estabeleçam "pausas regulares, assentos no local, programa de ginástica laboral preparatória (antes do início do expediente) e compensatória (durante a jornada) programas de orientação sobre postura, levantamento e 


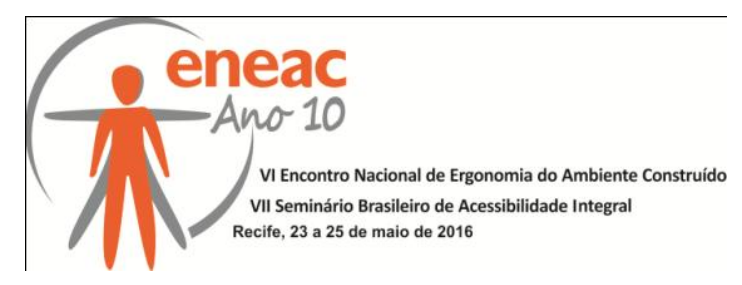

movimentação de cargas de forma segura introdução de rodízios planejados, visando relaxar determinados grupos musculares mais utilizados em umas tarefas do que em outras."

\section{METODOLOGIA}

A Análise Ergonômica do Trabalho (AET) estuda a situação do trabalho visando adaptá-la ao homem a partir da análise das condições técnicas, ambientais e organizacionais, buscando revelar as diferenças entre o trabalho formal e o real. A mesma divide-se em três fases sequenciais, onde a primeira, a análise da demanda, tem o objetivo identificar os problemas a serem estudados a partir de uma negociação com as partes envolvidas, delimitando a área de atuação do estudo. A segunda fase, a análise da tarefa, voltou-se para as condições do trabalho e do ambiente do trabalhador. Nessa fase fez-se a descrição detalhada do que envolve o sistema escolhido e quais as exigências ergonômicas de trabalho. E por último a terceira fase, a análise das atividades, onde analisa-se os comportamentos de trabalho, que vão desde os movimentos dos trabalhadores até as estratégias utilizadas pelo posto de trabalho.

Após essas fases de estudo descritas anteriormente, formula-se um diagnóstico para evidenciar os possíveis problemas encontrados e então ser possível gerar recomendações ergonômicas adequadas.

O levantamento dos dados se sucedeu por meio de visitas realizadas nos dias da semana de maior movimento no pet shop, quinta e sexta-feira. Foram feitas filmagens, fotos e entrevista com os trabalhadores e o administrativo, afim de identificar queixas.

Um dos métodos utilizados para levantamento inicial de dados e primeiro diagnóstico sucedeu-se através do questionário LEST (Laboratoire d'Economie et Sociologie du Travail). Ele é estruturado de forma a abordar todos os aspectos do local de trabalho de forma geral, englobando questões como:

- Os dados pessoais gerais dos trabalhadores como qualificação, sexo, idade, escolaridade;

- A definição da atividade que dizem respeito à função, tempo de exercício, jornada diária de trabalho, intervalos, etc.;

- Fatores ambientais como iluminação, ventilação, ruído e temperatura do local de trabalho;

- Temas ligados a saúde do trabalhador em aspectos físicos e psicológicos.

O resultado do LEST se dá numa escala de 0 a 10, e mostra para cada variável analisada se o trabalho é satisfatório ou prejudicial.

Para análise mais detalhada das posturas críticas que envolvem as atividades executadas pelas funcionárias, utilizou-se o método RULA (Rapid Upper Limp Assessment) com o uso do software Ergolândia.

O método RULA avalia danos potenciais aos membros superiores. Cardoso Junior (2006) ressalta que o método RULA permite observar e utilizar os dados referentes ao posicionamento de braço, antebraço e pescoço, ponto em que outros métodos deixam a desejar.

Para aplicação do método citado anteriormente utilizou-se filmagens feitas durante a execução de todo um ciclo de banho e secagem. Com isso foi proposta a separação da 


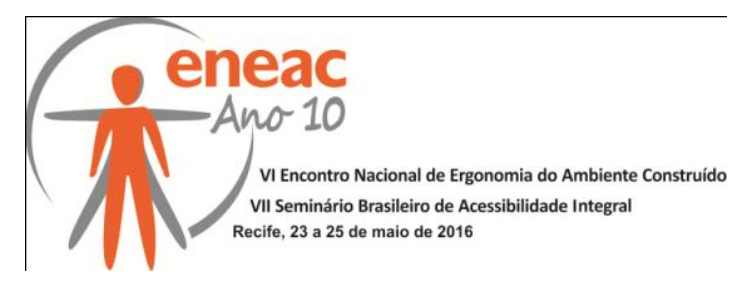

atividade em uma série de ações, para poder melhor considerar efeitos relacionados às posturas adotadas.

Ainda foram realizadas medições no posto de trabalho para avaliar à exposição a fatores ambientais como nível de ruído, vibrações, luminosidade e temperatura. Também foi feito o mesmo para o ambiente físico, realizando medidas de dimensões dos móveis e também espacial com o propósito de propor um novo layout.

\section{DESENVOLVIMENTO}

\subsection{Análise da Tarefa e da Atividade}

O posto de trabalho em que o estudo será focado é o da higienização dos animais no pet shop. Existem três funcionárias responsáveis pela tarefa mais um que se divide entre a função de motorista e de banhista, dependendo da demanda. Os funcionários trabalham oito horas por dia, existindo a possibilidade de realizarem hora extra caso haja um grande fluxo de animais em determinado dia. Os funcionários realizam três paradas ao longo do dia, uma hora destinada ao almoço e mais meia hora que normalmente eles dividem em 15 minutos no período matutino e o restante no período vespertino.

Com enfoque na tarefa realizada, os funcionários ao começar um procedimento com um cão ou gato são responsáveis pela finalização do mesmo, ou seja, se um funcionário lavou o cachorro, ele deve secá-lo e realizar os acabamentos finais, com exceção se o procedimento for tosar, nesse caso apenas um funcionário possui treinamento para executar essa atividade.

Dentro do processo de higienização há dois subprocessos que merecem destaques ao serem analisados, são eles: banho e secagem. Esse destaque deve-se por ambos os processos serem os mais demorados, cada um para ser realizado dispende de 10 a 20 minutos do trabalhador, além do que para um resultado de qualidade esses dois subprocessos devem ser realizados com excelência.

O banho é uma subtarefa que ao ser realizada pelo funcionário exige uma postura estática na sua maior parte do tempo dos membros inferiores e dinâmica dos membros superiores. Há movimentação intensa dos membros superiores tanto ao enxaguar o animal, que é feita de maneira continua mesmo quando o sabão ou o xampu é colocado na pelagem do pet, pois a estratégia utilizada pelos funcionários é de a ducha estar posicionada em uma mão e o restante das tarefas que devem ser realizadas simultaneamente feitas com a outra.

Analisando o segundo subprocesso citado anteriormente, a secagem, a postura estática dos membros inferiores e a dinamicidade dos membros superiores também estão presentes. $O$ manuseio de um instrumento em cada mão também é uma característica que continua existindo, nesse subprocesso o que ocorre é o secador em uma mão e escova em outra para pentear o animal.

Duas características são importantes de serem ressaltadas enquanto o animal é seco. Primeiro, a diferença entre o trabalho prescrito e o real. No trabalho prescrito antes de se usar o secador deve-se retirar o excesso de água do pet com a toalha, contudo isso não é feito. $O$ animal depois do último enxague é colocado praticamente direto na secagem, apenas é seca a região da cabeça do animal, não de todo o corpo. A segunda característica é de que os funcionários dificilmente desligam os secadores, portanto o ruído proveniente do equipamento é praticamente contínuo durante toda jornada de trabalho. A figura 1 ilustra a atividade de banhar e secar o animal. 


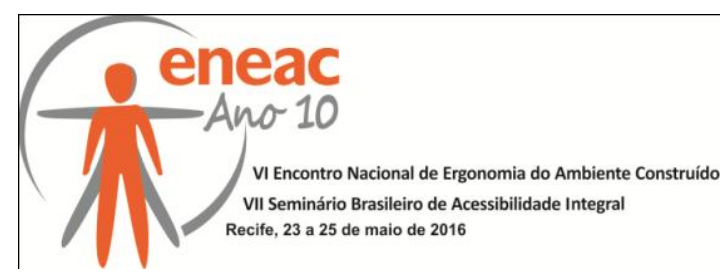

Figura 1 - Banho e secagem no pet shop

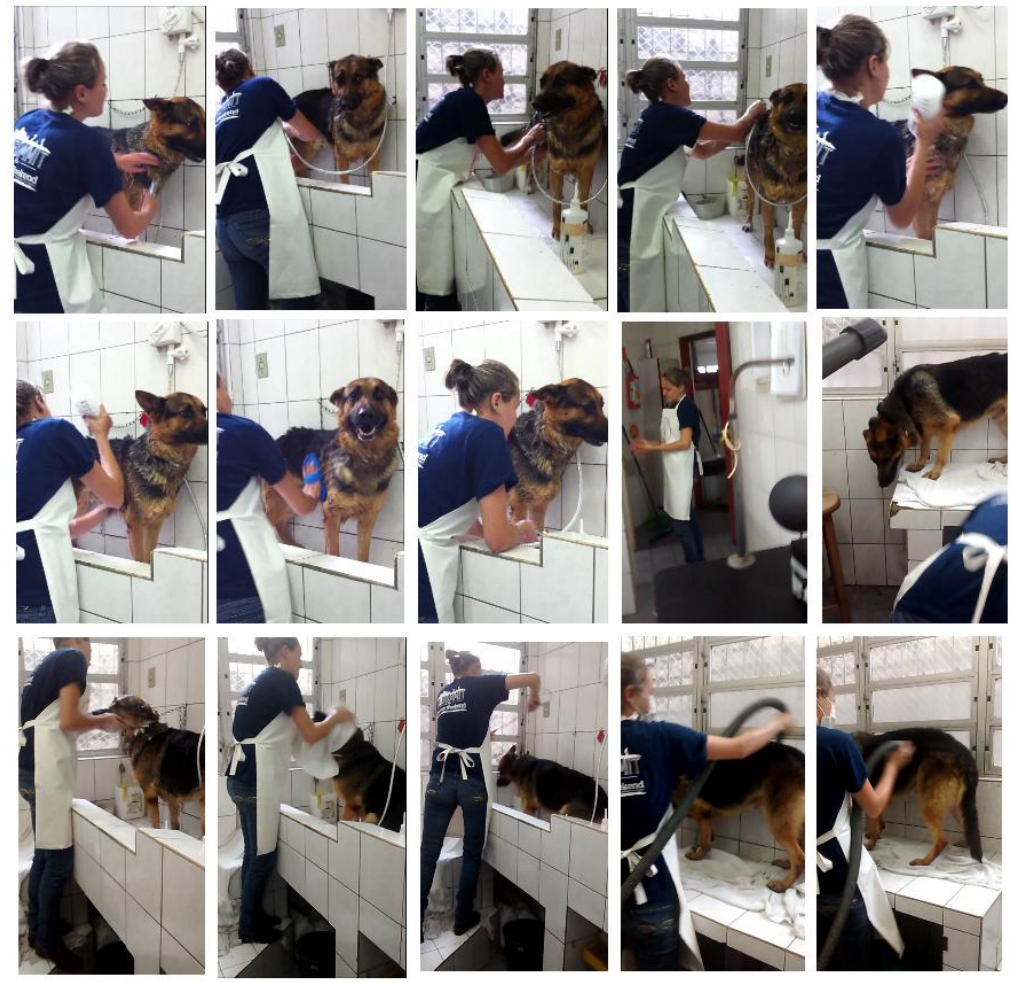

\section{RESULTADOS}

\subsection{Diagnóstico ergonômico}

\subsubsection{Análises ambientais}

Analisaram-se as condições ambientais nos aspectos relacionados ao ambiente: sonoro, térmico, lumínico e o espaço físico, tanto a parte de mobiliário quanto de layout, para realização das atividades de banho e tosa.

No que diz respeito ao conforto térmico, a temperatura é mantida com o auxilio de ar condicionado, as janelas do ambiente ficam obrigatoriamente fechadas para que o pêlo proveniente dos animais não seja levado para fora e haja reclamação dos vizinhos, existindo ventilação natural apenas por uma porta de grade que fica ao fundo, cerca de 8 metros do ambiente de trabalho.

O uso dos sopradores e secadores, que ficam ligados por praticamente todo o período, contribuem para a elevação da temperatura do local, sendo necessário que 0 ar condicionado permaneça ligado por toda jornada. Mesmo com as variáveis apresentadas acima o IBUTG calculado se mostrou dentro das normas para a atividade praticada.

Investigando o local e realizando as medidas antropométricas necessárias concluiu-se não haver problemas com relação ao mobiliário. A banheira encontra-se a $80 \mathrm{~cm}$ do piso acabado (considerando o fundo da banheira) e possui apoio para os cotovelos (com altura 


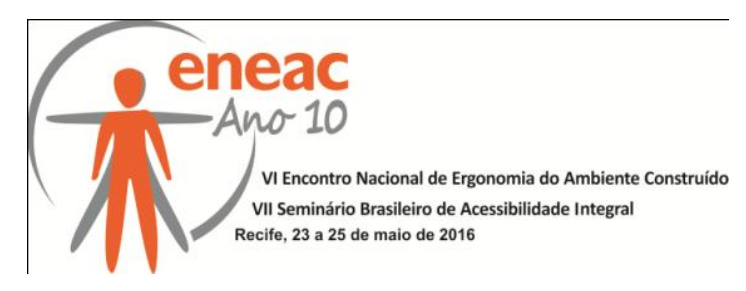

de $103 \mathrm{~cm}$ ), e a mesa de secagem possui altura de $82 \mathrm{~cm}$. Medidas que ficam dentro do especificado para uma atividade pesada, que é de 70 a $85 \mathrm{~cm}$, para mulheres.

Porém em relação ao fluxo das funcionárias dentro do local de trabalho e a distribuição do mobiliário foram observados pontos que poderiam ser melhorados. Constatou-se um gargalo entre a mesa de tosa e a banheira, acarretando em uma passagem com apenas $50 \mathrm{~cm}$, impossibilitando um bom transito neste local, que é humano e animal. Outro fator é a abertura da porta principal, funcionários e a maioria dos animais passam por ela, e a mesma pode ser aberta parcialmente $(74 \mathrm{~cm})$, pois a mesa onde se realiza a secagem não permite esta abertura, como é mostrado na Figura 2.

Verificou-se durante a análise da atividade que determinados utensílios não estavam presentes no posto de trabalho da funcionária ou então estavam longe do seu alcance normal, exigindo deslocamentos durante a operação para outros postos e/ou invadindo o espaço de outros durante seu trabalho. Exemplo disto, são as escovas para pêlo utilizadas durante a secagem, elas ficam localizadas somente na mesa de tosa dentro do ambiente de banho como sinaliza a figura 2.

Figura 2 - Planta baixa do banho e tosa com sinalização de pontos críticos

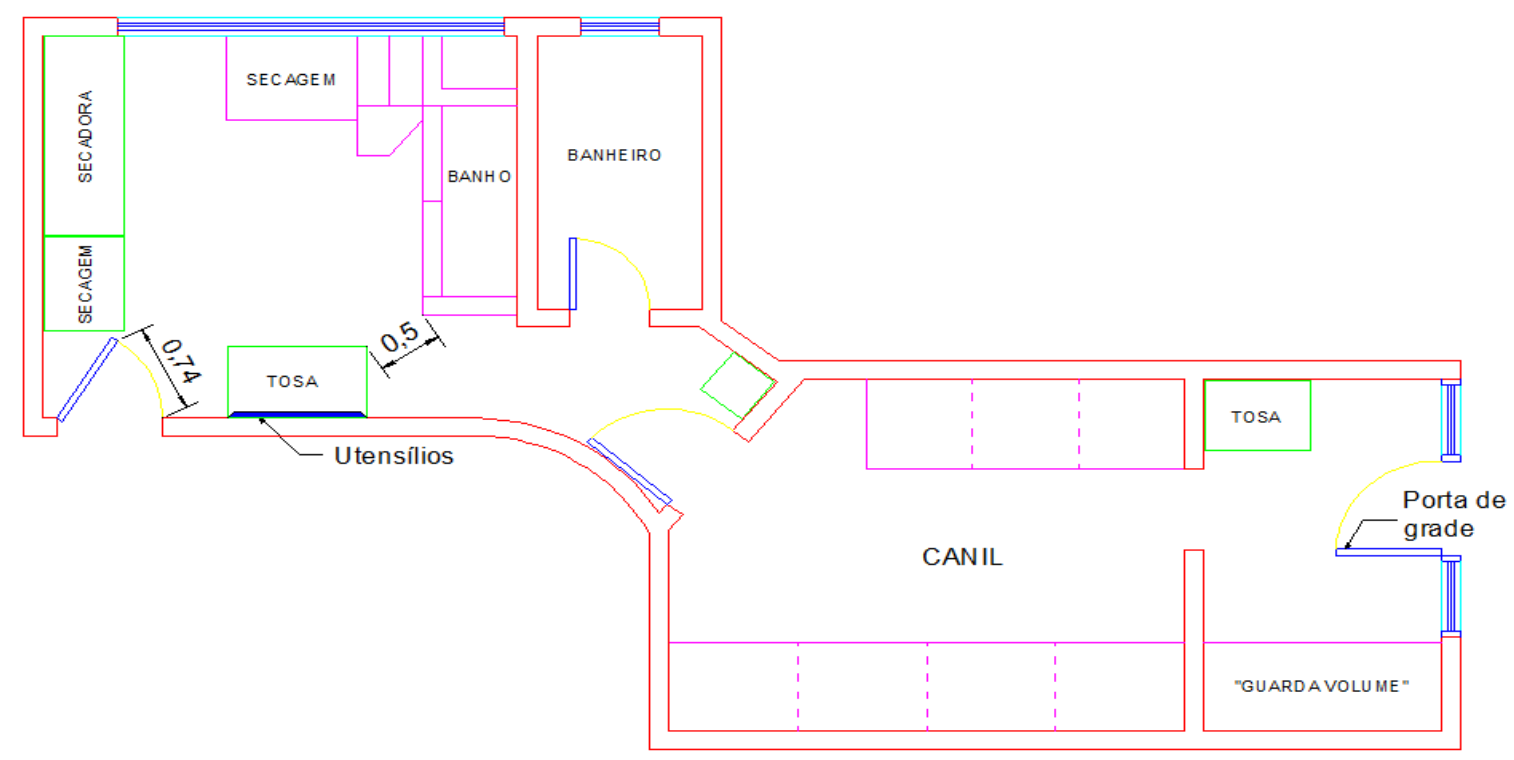

Com uma análise mais detalhada dos fluxos para realização do banho, secagem e tosa, obtém-se a planta de fluxos, figura 3. Observa-se pontos em que há mais fluxos, o que possivelmente reduz a eficiência do trabalho e ocasionalmente pode acarretar em acidentes. 


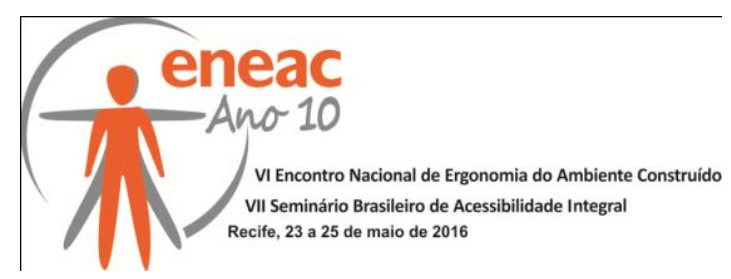

Figura 3 - Fluxos existentes

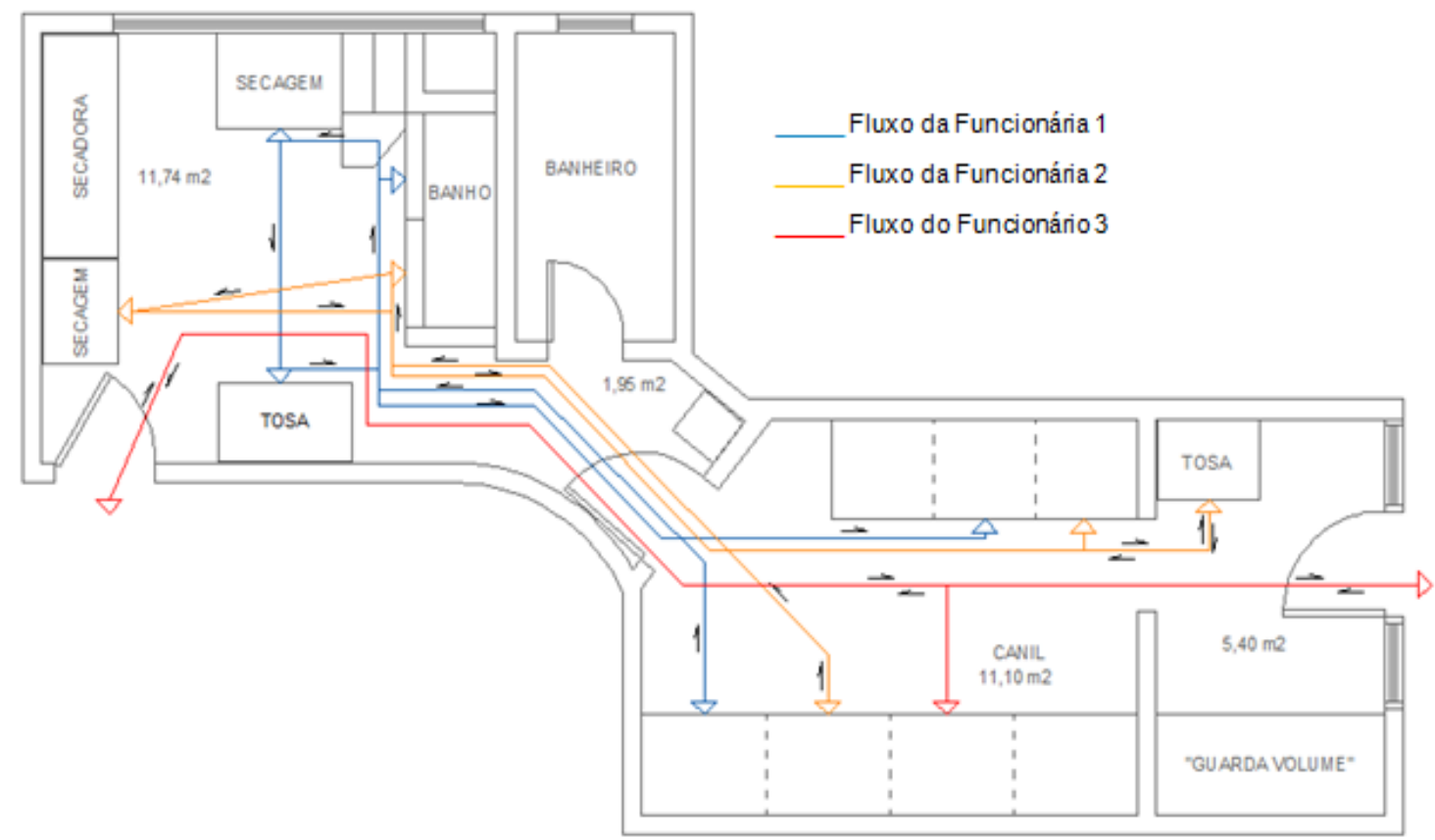

Para representar os animais que chegam para o banho e são deixados no canil e também o momento em que eles são entregues, desenhou-se o fluxo em vermelho. Deve-se ressaltar que pela porta que se encontra no espaço de banho e tosa o fluxo é mais intenso em relação à porta de fundos. Isso decorre do fato deste espaço ser a entrada de animais trazidos por seus proprietários (maior quantidade) em horários não definidos. Já pela porta dos fundos, chegam os animais que a empresa busca, sendo os horários de fluxo mais definidos e todos de uma só vez.

Por conta dos sopradores e secadores, e também pelo barulho dos animais, o ruído medido ultrapassou o máximo permitido, chegando a $92 \mathrm{~dB}(\mathrm{~A})$ quando estes aparelhos estavam ligados e $75 \mathrm{~dB}(\mathrm{~A})$ desligados.

Na norma NBR 10152, 1997 da ABNT é descrito que não importando a situação ou atividade, ruído acima dos $75 \mathrm{~dB}(\mathrm{~A})$ passa a ser um agente de desconforto, podendo haver intangibilidade da linguagem, distrações e irritabilidade. $E$ acima dos $80 \mathrm{~dB}(\mathrm{~A})$ as pessoas mais sensíveis podem sofrer perda de audição.

Verificou-se que as funcionárias não fazem o uso de EPI's cedidos pela empresa. Foi mencionado por colaboradores durante visita técnica ao pet shop, que a utiização de EPI's (protetores auriculares) não permitiria a audição de telefone utilizado para comunicação entre os setores comercial e de banho e tosa.

$\mathrm{Na}$ investigação do ambiente lumínico observou-se presença de luz natural e artificial. A medição dos níveis de iluminamento foi realizada em um dia nublado e o resultado obtido foi de 324 lux. Levando-se em consideração a exigência à que os funcionários estão submetidos por seus superiores em relação à qualidade do serviço e sabendo-se que os serviços de banho, tosa e secagem são atividades que exigem aferição visual, o nível exigido de iluminância ficou abaixo do esperado, devendo ser de 500 lux. 


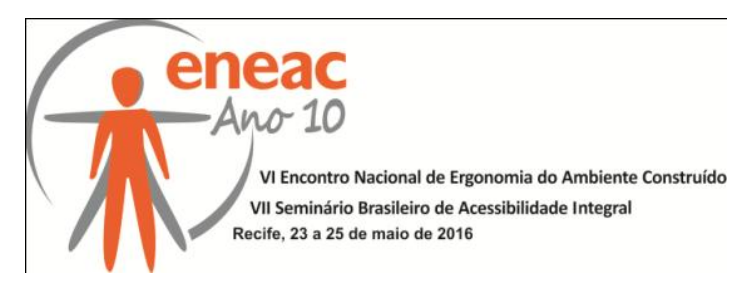

\subsubsection{Questionário LEST}

O questionário LEST permitiu a análise do local de trabalho por diversos aspectos, mostrando em quais situações o trabalho se mostra satisfatório ou prejudicial através da legenda apresentada. $O$ questionário aplicado gerou gráficos que englobaram no primeiro momento 5 aspectos, divididos nas dimensões apresentadas no gráfico 1. Posteriormente foram subdivididos estes cinco aspectos em dezesseis variáveis (fatores), gerando a gráfico 2.

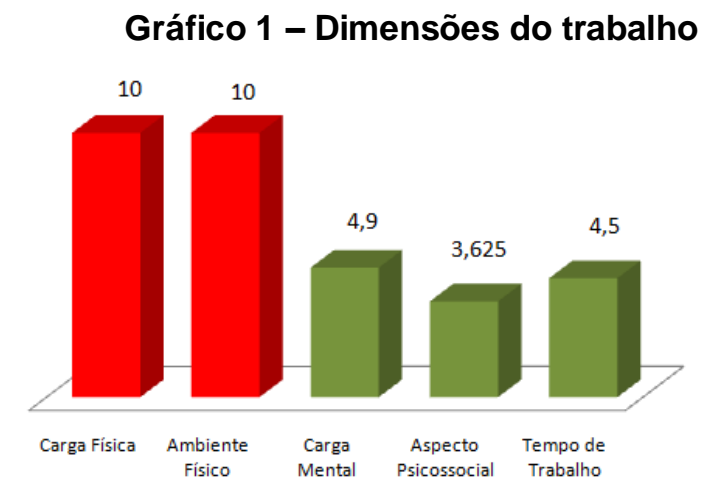

\section{Gráfico 2 - Fatores analisados para divisão das dimensões}
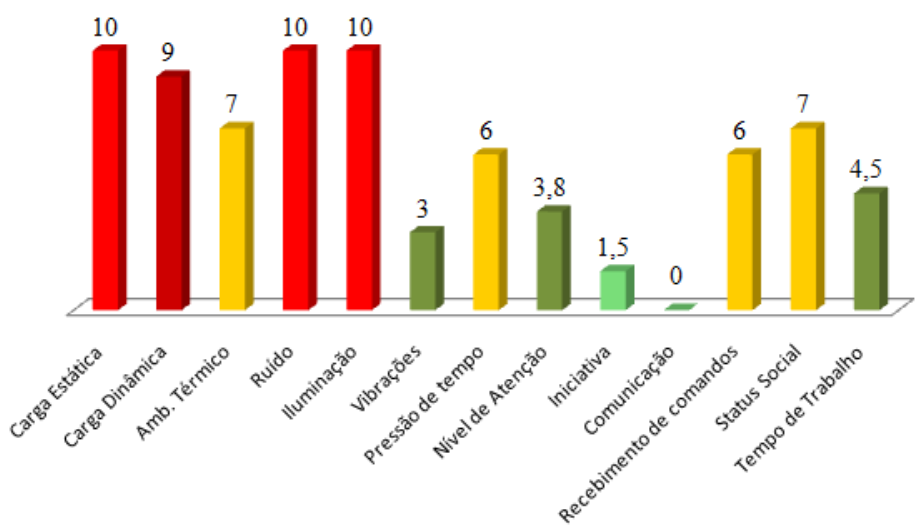

\begin{tabular}{|l|l|l|}
\hline \multicolumn{2}{|c|}{ Legenda } \\
\hline & $0,1,2$ & Situação satisfatória. \\
\hline & $3,4,5$ & Leve desconforto. Algumas melhoras poderiam trazer mais comodidade ao trabalhador. \\
\hline 6,7 & Desconforto médio. Há risco de fadiga. \\
\hline 8,9 & Forte desconforto. Existência de fadiga. \\
\hline 10 & Nocivo. \\
\hline
\end{tabular}

Observa-se, como apresentados anteriormente, que os níveis de ruído e iluminação também se apresentam nocivos a saúde do trabalhador pelo método LEST.

A carga estática se mostrou também altamente nociva e as exigências de carga dinâmica com forte existência de desconforto, necessitando medidas corretivas nos dois pontos levantados. 


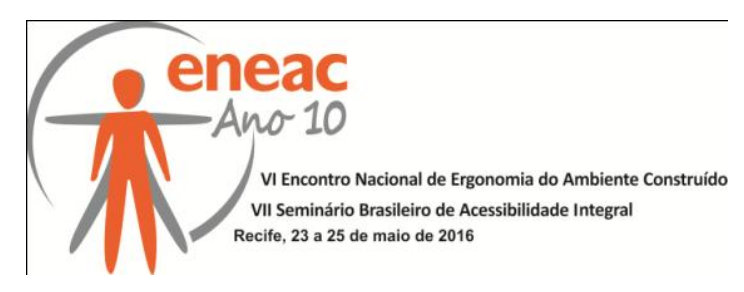

\subsubsection{Avaliação postural utilizando o método RULA}

A avaliação pelo método RULA sucedeu-se avaliando um vídeo filmado e separando-o em ações semelhantes. Chegou-se ao total de 10 tarefas, tendo sido cada uma cronometrada individualmente e posteriormente calculou-se a porcentagem de tempo que cada uma demandava em relação ao total, conforme apresentado na tabela 1.

Tabela 1 - Porcentagem de tempo de cada tarefa

\begin{tabular}{|l|l|l|l|}
\hline Tarefa & $\begin{array}{l}\text { Tempo (minutos e } \\
\text { segundos) }\end{array}$ & Porcentagem & \multicolumn{1}{|c|}{ Descrição da Tarefa } \\
\hline 1 & $1: 04,70$ & $9,23 \%$ & Lavação patas, parte frontal, posterior e enxágüe \\
\hline 2 & $0: 56,23$ & $8,03 \%$ & Lavação barriga, costas e enxágüe \\
\hline 3 & $0: 46,67$ & $6,66 \%$ & Passar condicionador e escovar com escova \\
\hline 4 & $0: 09,57$ & $1,37 \%$ & Limpar escova utilizada \\
\hline 5 & $1: 15,84$ & $16,53 \%$ & Lavação da cabeça e enxágüe \\
\hline 6 & $1: 01,53$ & $8,79 \%$ & Atividades que exigiram deslocamento \\
\hline 7 & $0: 16,13$ & $2,30 \%$ & Secar com a toalha \\
\hline 8 & $0: 13,04$ & $1,87 \%$ & Mudança de posto (da banheira para secagem) \\
\hline 9 & $0: 02,65$ & $0,38 \%$ & Ação para ligar o secador \\
\hline 10 & $3: 14,31$ & $44,84 \%$ & Secagem do animal \\
\hline Total & $9: 00,67$ & $100,00 \%$ & Total das tarefas \\
\hline & & &
\end{tabular}

Para as três primeiras atividades listadas, que somam 23,92\% do tempo (maior percentual em relação a atividade de banho), surgiu o maior risco encontrado, estabelecendo nível de ação número 3, que sugere investigação e posterior introdução de mudanças.

Porém, o nível de ação que mais se repetiu foi o 2, que sugere se realizar investigações, pois mudanças poderão ser necessárias, como pode ser visto na tabela 2.

Tabela 2 - Resultado do método RULA

\begin{tabular}{|l|c|c|c|}
\hline \multicolumn{1}{|c|}{ Atividade } & Pontuação & $\begin{array}{c}\text { Nível de } \\
\text { Ação }\end{array}$ & Ação \\
\hline $\begin{array}{l}\text { Lavação patas, parte frontal, posterior e } \\
\text { enxágüe }\end{array}$ & 6 & 3 & $\begin{array}{l}\text { Deve-se realizar investigação e } \\
\text { serem introduzidas mudanças }\end{array}$ \\
\hline Lavação barriga, costas e enxágüe & 6 & 3 & Deve-se realizar investigação e \\
\hline
\end{tabular}




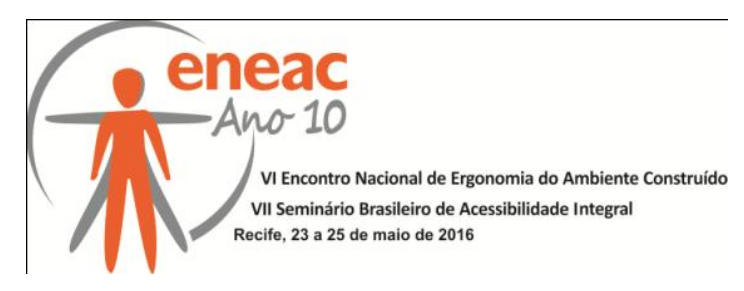

\begin{tabular}{|l|c|c|l|}
\hline & & & serem introduzidas mudanças \\
\hline Passar condicionador e escovar com escova & 6 & 3 & $\begin{array}{l}\text { Deve-se realizar investigação e } \\
\text { serem introduzidas mudanças }\end{array}$ \\
\hline Limpar escova utilizada & 2 & 1 & Postura aceitável \\
\hline Lavação da cabeça e enxágüe & 3 & 2 & $\begin{array}{l}\text { Deve-se realizar uma observação, } \\
\text { podem ser necessárias mudanças }\end{array}$ \\
\hline Atividades que exigiram deslocamento & 1 & 1 & Postura aceitável \\
\hline Secar com a toalha & 3 & 2 & $\begin{array}{l}\text { Deve-se realizar uma observação, } \\
\text { podem ser necessárias mudanças }\end{array}$ \\
\hline Mudança de posto (da banheira para secagem) & 4 & 2 & $\begin{array}{l}\text { Deve-se realizar uma observação, } \\
\text { podem ser necessárias mudanças }\end{array}$ \\
\hline Ação para ligar o secador & 4 & 2 & $\begin{array}{l}\text { Deve-se realizar uma observação, } \\
\text { podem ser necessárias mudanças }\end{array}$ \\
\hline Secagem do animal & 4 & 2 & $\begin{array}{l}\text { Deve-se realizar uma observação, } \\
\text { podem ser necessárias mudanças }\end{array}$ \\
\hline
\end{tabular}

\subsection{Recomendações}

Diante dos problemas identificados, verificou-se a necessidade por melhorias que tornarão o processo mais eficiente e com consequentes melhorias na saúde de seus funcionários. Pensando nisso, foram sugeridas recomendações para solucionar e/ou amenizar tais problemas. Para algumas delas utilizou-se como referência o Livro "Pontos de Verificação Ergonômica" (P.V.) formulado pela ILO - International Labour Office, que propõe soluções práticas para melhoria da segurança, da saúde e das condições de trabalho.

Como já citado, uma das maiores reclamações das funcionárias foram as dores de coluna proveniente de inclinações necessárias para dar banho aos animais. Para tal problema, recomenda-se que sejam realizadas pausas regulares durante as atividades e para isso é interessante que haja assentos no local. (P.V. 64 e P.V. 122)

Um aspecto importante é que a funcionária esteja preparada e em condições físicas adequadas para as tarefas, para isso recomenda-se que sejam praticadas ginástica laboral preparatória antes e depois do expediente. No entanto essas recomendações não seriam suficientes se as funcionárias não tiverem consciência da importância de uma posição adequada, por isso faz-se necessária uma conscientização dessas recomendações.

Com relação aos riscos ambientais, tais como elevado índice de ruído, já comprovado no presente artigo, recomenda-se o uso de protetores auriculares. Para solucionar o fato apontado pelas funcionárias (descrito anteriormente no artigo, item 4.1.1) propõe-se a instalação de alertas luminosos posicionados estrategicamente perto das bancadas, assim toda vez que o telefone tocar esses alertas irão ascender, dispensando a atenção provida pela audição. (P.V. 90) 


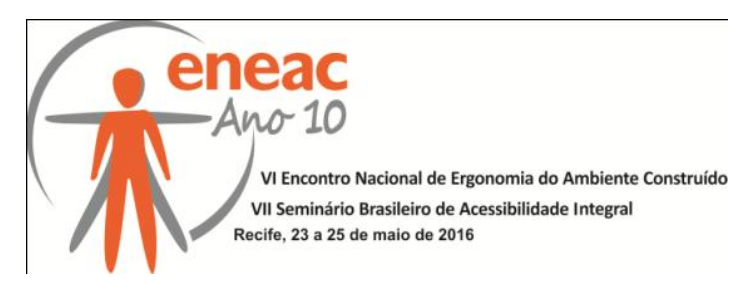

Outro aspecto importante é a qualidade do ar disponível no local e o contato excessivo com os animais. Para isso recomenda-se o uso de máscaras e aventais. Tais procedimentos minimizarão o risco de contrair doenças provenientes dos cães ou gatos. (P.V. 100)

A fim de promover uma disposição da mobilha que contribua com o fluxo e que favoreça a realização das atividades, foi desenvolvido um novo layout. A proposta basicamente consiste na troca dos ambientes, onde era o canil passou a ser a área de banho e tosa e vice versa. Por se tratar um ambiente maior e com uma geometria favorável, essa troca permitiu uma melhor disposição dos móveis e equipamentos facilitando o fluxo das várias atividades, como podemos perceber na figura 4.

Figura 4 - Fluxo das atividades

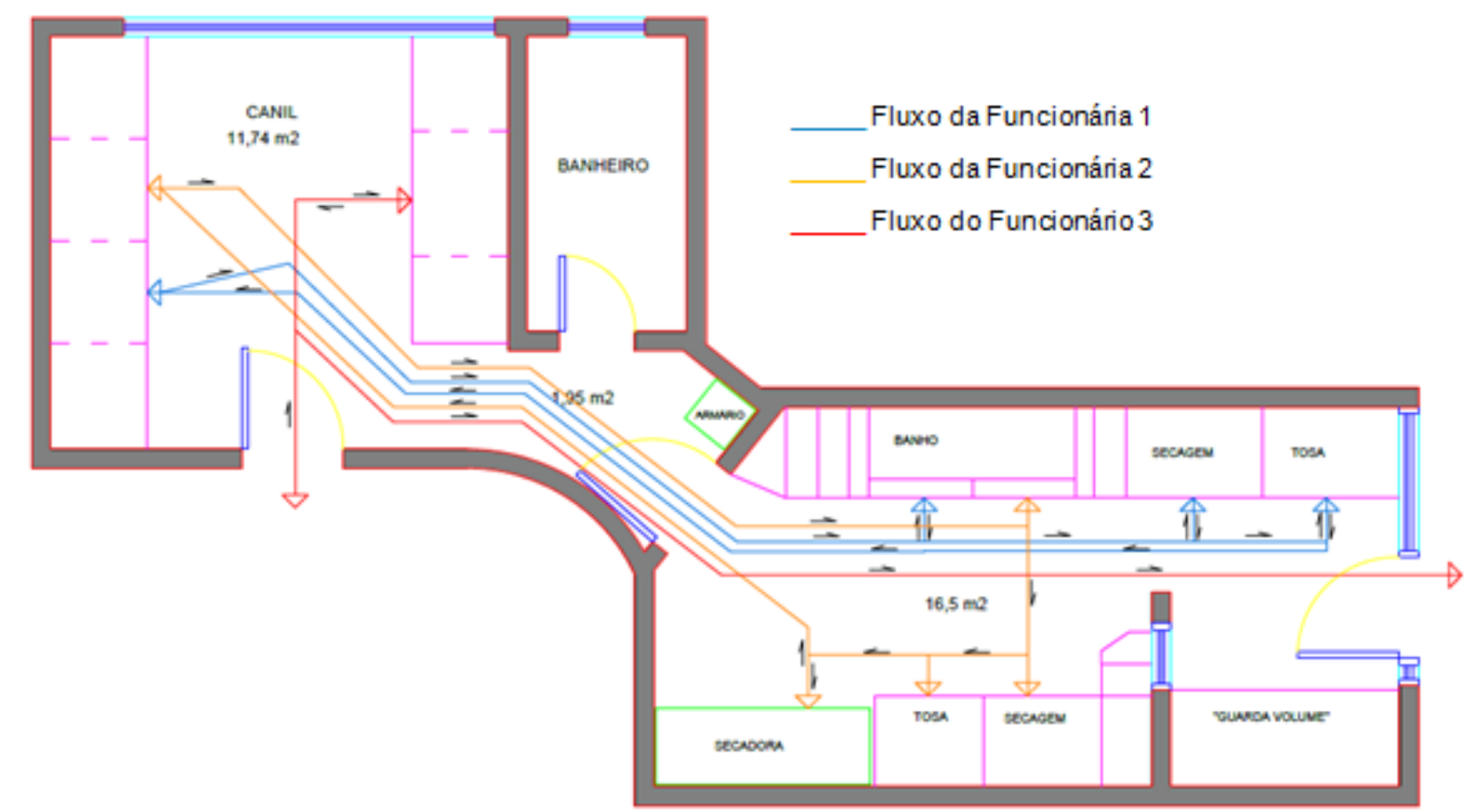

Seguindo com as propostas, agora relacionado com as instalações, segue lista de possíveis soluções para cada problema identificado:

- Má disposição das ferramentas de tosa: para cada bancada de tosa, recomenda-se a disponibilidade de tais ferramentas, evitando deslocamentos desnecessários. (P.V. 5)

- Escada escorregadia: para a escada que serve como apoio para a banheira, é necessário que se aplique antiderrapantes, a fim de evitar possíveis acidentes, tanto com funcionárias, quanto com animais. (P.V. 3)

- Ambiente térmico: levando em conta o uso constante dos sopradores e a falta de circulação, o ambiente poderá ficar demasiadamente quente. Para solucionar tal problema, propõe-se a instalação de um sistema de ar condicionado, e também de exautores para reduzir o mau cheiro proveniente do processo de lavagem. (P.V. 82)

- Ambiente lumínico: para suprir a necessidade por um ambiente mais luminoso, é necessário que sejam instaladas lâmpadas que possam iluminar o mínimo necessário exigido pela norma. (P.V. 75 e 76) 


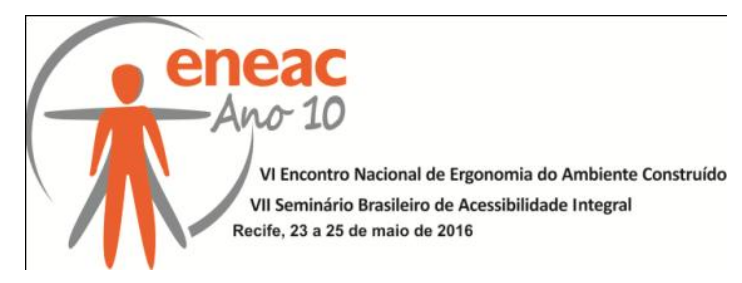

\section{CONCLUSÃO}

Este artigo apresentou o estudo ergonômico que foi realizado em um Pet Shop segundo a metodologia da Análise Ergonômica do Trabalho. A partir do conhecimento do mercado de pet shops, que cresce significativamente a cada ano assim como o número de animais domésticos nas residências brasileiras, verifica-se a necessidade de um estudo a fim de nortear o desenvolvimento e crescimento de futuros estabelecimentos semelhantes ao estudado.

A inadequação do arranjo espacial mostrou-se como causa de possível desgaste por parte dos funcionários em seu cotidiano de trabalho, bem como os níveis de ruído e iluminação, que por estarem desconformes estão em níveis capazes de afetar as atividades diárias. Porém, deve ser observado que em muitas ocasiões há uma resistência por parte dos funcionários para realização de mudanças necessárias para melhorias ergonômicas. Nestes casos, deve ser reforçado por parte da empresa a conscientização e incentivo ao uso de boas práticas por cada funcionário.

A metodologia utilizada mostrou-se capaz de identificar e avaliar os riscos ergonômicos oferecidos pelo trabalho através da aplicação da ferramenta RULA e do questionário LEST. Conseguiu-se formular um diagnóstico consistente demonstrando as situações encontradas e os pontos que poderiam haver melhorias na atividade. Através das recomendações, visando o bem-estar do trabalhador, propuseram-se adaptações ergonômicas que se demonstram efetivas a atividade desenvolvida, e muitas delas facilmente solucionáveis para empresa em questão executar.

\section{REFERÊNCIAS BIBLIOGRÁFICAS}

HECKSHER, Suzana Dantas; BRITO, Philippe Martins Franco; MARIANO, Ludmila Tomaz. Análise Ergonômica do Trabalho no Setor de Trefilação de uma Siderúrgica de Grande Porte. In: ENCONTRO NACIONAL DE ENGENHARIA DE PRODUÇÃO - ENEGEP, 2009.

RIBEIRO, Ana Luisa Dias et al. Analise Ergonômica do Trabalho: Aplicação da Metodologia no Posto de Banho e Tosa em um Pet Shop. In: ENCONTRO NACIONAL DE ENGENHARIA DE PRODUÇÃO - ENEGEP, 2011.

CARDOSO JUNIOR, Moacyr Machado. Avaliação Ergonômica: Revisão dos Métodos para Avaliação Postural. Revista Produção: Online, Florianópolis, v. 6, n. 3, p.133-154, dez. 2006. Disponível em: $<$ www.producaoonline.inf.br>. Acesso em: 01 dez. 2015.

SAMPAIO, Priscila Goncalves Vasconcelos; MARQUES, Blake Charles Diniz. Análise Ergonômica do Trabalho numa Fábrica de Produtos de Limpeza. In: ENCONTRO NACIONAL DE ENGENHARIA DE PRODUÇÃO - ENEGEP, 2011.

VERGARA, Lizandra Garcia Lupi; RIBET, Lucie Elisa. Adequação Ergonômica do Berçário do Núcleo de Desenvolvimento Infantil $\mathrm{Da}$ Ufsc. Ação Ergonômica: Revista Brasileira de Ergonomia, Florianópolis, v. 7, n. 2, p.43-60, 2012.

TAKEDA, Fabiano et al. Avaliação Biomecânica dos Trabalhadores de Linha Contínua de Cortes de Frangos. In: ENCONTRO NACIONAL DE ENGENHARIA DE PRODUÇÃO - ENEGEP, 2010.

GENEBRA. International Labour Office. Ministério do Trabalho e Emprego (Org.). Pontos de verificação ergonômica: Soluções práticas e de fácil aplicação para melhorar a segurança, a saúde e as condições de trabalho. São Paulo, 2001. 329 p. Tradução: Cassio de Arantes Leite. 